\title{
Proposal for Minimal Standards for Descriptions of New Species and Biotypes of the Genus Brucella
}

\author{
M. J. CORBEL AND W. J. BRINLEY MORGAN \\ Central Veterinary Laboratory, Weybridge, England
}

\begin{abstract}
Following the introduction of new statutes agreed at the Xth International Congress for Microbiology held in Mexico City in 1972, the International Committee for Systematic Bacteriology has requested subcommittees on taxonomy to propose minimal standards for the descriptions of new taxa. Consequently a proposal for minimal standards for the descriptions of new species and biotypes of the genus Brucella Meyer and Shaw (22) has been prepared. As procedures recommended by the Subcommittee on Taxonomy of the Genus Brucella (34) for subdivision within the genus have been employed successfully for a number of years, present emphasis has been placed on the minimal standards for recognition of an organism as a member of the genus. This aspect is particularly important as it is now recognized that a number of genetically unrelated gram-negative organisms bear a superficial resemblance to members of the genus Brucella. To avoid confusion and misidentification it is essential that a comprehensive system for identification at the generic level should be adopted. Recommendations for this are contained in the present proposal along with suggestions for minimal requirements for subdivision within the genus. Comments will be welcomed so that eventually this paper can be used as a basis for preparing a document covering full details of techniques and procedures.
\end{abstract}

\section{PROPOSAL}

In proposing the establishment of new species or biotypes of the genus Brucella it is essential that in the first instance the organisms on which these claims are based should be shown to possess the characteristics of this genus. Subsequently, it must be shown that they differ consistently and significantly from previously designated species or biotypes.

Properties of primary importance in identification of members of the genus Brucella. At present, no single criterion is known which would enable an organism to be identified unequivocally as a member of the genus Brucella. Thus, in assessing any new isolate it is essential that a number of parameters should be examined before drawing any conclusions as to identity.

As a first step, it is recommended that the general bacteriological characteristics of the organism should be examined and shown to be consistent with those of the genus Brucella. Individually, most of these characteristics are not unique to the genus Brucella, and variations also occur within the genus. Collectively, these

\footnotetext{
${ }^{1}$ Prepared on behalf of the Subcommittee on the Genus Brucella of the International Committee for Systematic Bacteriology.
}

characteristics enable the status of an organism in relation to the genus to be defined in the majority of cases.

The Subcommittee recommends that, when examining a strain for the possibility of its inclusion in the genus Brucella, the examination should include, as a minimum, a search for the following.

Morphology and staining. Shape; size; capsules; endospores; fimbriae; flagella and motility; Gram reaction; Zeihl-Nielsen reaction (acid fastness); bipolar staining.

Biochemical and physiological. Form of metabolism (oxidative or fermentative); aerobiosis or anaerobiosis; dependence on $\mathrm{CO}_{2}$ for growth; growth in a chemically defined medium with the ammonium ion as sole nitrogen source; dependence on or stimulation by amino acids; growth factor requirements; oxidation of carbohydrates and amino acids; catalase; oxidase; urease; production of $\mathrm{H}_{2} \mathrm{~S}$ from sulfur-containing amino acids; reduction of nitrate; utilization of citrate; production of indole; production of acetylmethylcarbinol (Voges-Proskauer test) and acid from glucose (methyl red test); production of acid in "sugar peptone waters"; reaction in litmus milk; production of $\beta$-galactosidase $\quad(o$-nitrophenol- $\beta$-D-galactopyranoside 
test); range of growth temperatures; optimum $\mathrm{pH}$ for growth.

Cultural characteristics. Growth on peptone agar; growth on tryptose or Trypticase (BBL) soy agar; growth on peptone agar plus $5 \%$ (vol/vol) serum; growth in liquid media with production of turbidity, pellicle, or sediment; growth in the presence of tellurite, selenite, or bile salts.

Sensitivity to antibiotics. Not very reliable, but tests for sensitivity to tetracycline, rifampin and gentamicin could be made.

Sensitivity to dyes. Basic fuchsin, thionin.

Antigenic state. Examine colonies in obliquely transmitted light for their staining reaction to crystal violet and agglutinability in neutral acriflavine solutions. Examine cells for the presence of, and distribution of, $A$ and $M$ antigens and $\mathrm{R}$ antigens.

DNA. Deoxyribonucleic acid (DNA) base ratios and hybridization studies.

Protein composition. Electrophoretic patterns of acid-phenol-soluble proteins.

Absorption spectra. Major cytochromes.

Phage sensitivity. To selected phages.

Pathogenicity. To guinea pigs and mice.

General properties of the genus Brucella. (i) Morphology. The morphological features of members of the genus are remarkably consistent. In the electron microscope or the light microscope, they appear as coccobacilli or short rods, 0.5 to 0.7 by 0.6 to $1.5 \mu \mathrm{m}$, usually arranged singly, rarely in pairs or short chains. Capsules, flagella, and spores are always absent. Fimbriae have not been described. When growing intracellularly, the organisms appear to be surrounded by a vacuole on examination of negatively stained thin sections in the electron microscope. When examined in the light $\mathrm{mi}$ crosope, the organisms are nonmotile and are readily stained by conventional methods. They are gram negative, do not show bipolar staining, and are not acid fast to the standard ZiehlNielsen method.

(ii) Metabolism. Chemo-organotrophs; metabolism oxidative. All are obligate aerobes, although some strains require 5 to $10 \%$ added $\mathrm{CO}_{2}$ for growth, especially on primary isolation. Some strains can grow in a chemically defined medium with ammonium ion as sole nitrogen source (20); most strains produce better growth, and from a smaller inoculum, if multiple amino acids are added to the synthetic medium (16, 32).

Thiamin, nicotinamide, and biotin are required for growth; growth is often stimulated by calcium pantothenate. Meso-erythritol may also stimulate growth. Hemin (X factor) and nicotinamide adenine dinucleotide (coenzyme 1 or $\mathrm{V}$ factor) are not required.

Catalase positive; the oxidase reaction is usually positive, but $B$. neotomae and $B$. ovis are oxidase negative. Urea hydrolyzed to a variable extent. $\mathrm{H}_{2} \mathrm{~S}$ production from sulfur-containing amino acids is also variable. All reduce nitrates to nitrites except for $B$. ovis, which does not produce nitrite. Citrate is not utilized; indole and acetylmethylcarbinol are not produced, and the methyl red and Voges-Proskauer tests are negative. Litmus milk is not changed. Some strains show oxidative activity in Hugh \& Leifson's medium, although the reaction may be available. Most strains show no activity in conventional fermentation tests with sugars, although $B$. neotomae shows some fermentative activity. (These tests cannot be performed on $\mathrm{CO}_{2}$-dependent strains.) The $\alpha$-nitrophenol- $\beta$ D-galactopyranoside test is negative.

Growth will occur within the temperature range of 20 to $40 \mathrm{C}$, but the optimum temperature is $37 \mathrm{C}$. The optimum $\mathrm{pH}$ for growth is between $\mathrm{pH} 6.6$ and 7.4.

(iii) Cultural characteristics. Most Brucella strains grow poorly on peptone medium and will not grow from small inocula. Tryptose and Trypticase (BBL) soy provide for adequate growth, however. Growth may also be improved by the addition of 1 to $5 \%(\mathrm{vol} / \mathrm{vol})$ serum.

Growth in liquid medium shows moderate turbidity with slight sediment but no pellicle formation. $B$. canis produces a mucoid sediment. Little or no growth is produced in media containing bile salts, selenite, or tellurite.

Antibiotic sensitivity is not a reliable means of identification, but nearly all Brucella strains are sensitive to tetracycline, rifampin, and gentamycin. Resistance to these would suggest that the organisms were atypical of the genus.

Smooth (S) members of the genus are prone to spontaneous dissociation to nonsmooth variants in laboratory media, especially in static liquid culture. The nonsmooth forms include intermediate $(\mathrm{I})$, rough $(\mathrm{R})$, and mucoid $(\mathrm{M})$ variants. The various colonial forms of these may be distinguished by their appearance in obliquely transmitted light (17), their staining reaction with crystal violet (36), and their agglutinability in neutral acriflavine solutions (4). Strains of B. abortus, B. melitensis, $B$. neotomae, and $B$. suis are almost invariably smooth on primary isolation. $B$. ovis and $B$. canis strains are invariably nonsmooth and lack the specific surface antigens of the $\mathrm{S}$ forms. 
(iv) Surface antigens. Smooth Brucella species show complete cross-reactivity in slide agglutination tests with unabsorbed antismooth Brucella sera. Different quantitative distribution of the $A$ and $M$ surface antigens of smooth strains can be shown using monospecific antisera to these determinants. All smooth Brucella strains are agglutinated by anti-A, anti-M, or both anti-A and anti-M sera. Rough or mucoid strains are not agglutinated by these antisera but cross-agglutinate with antisera prepared against rough Brucella strains $(9,10)$.

It is recommended that the anti-rough serum should be prepared in rabbits using $R$ antigen isolated from the neotype strain of $B$. ovis $63 / 290$ by the method of Diaz and Bosseray (7). In performing agglutination tests on new isolates, it should be remembered that the antisera may contain naturally acquired antibodies to organisms unrelated to brucellae.

(v) Pathogenicity. All Brucella species are facultative intracellular parasites. Chronic infections can generally be produced on inoculation of smooth strains into guinea pigs or mice; it may be difficult to establish infection with nonsmooth isolates.

Infection by Brucella species generally results in a serological response to both intracellular and surface antigens and is accompanied by the development of delayed hypersensitivity to Brucella antigens.

In laboratory rodents, the organisms tend to localize in the organs of the reticuloendothelial system.

Additional properties of primary importance in identification of members of the genus Brucella. As systematic bacteriology is primarily concerned with establishing genetic relationships among bacteria, those methods which involve direct or indirect comparison of the bacterial genome are likely to yield the most valid results.

In the case of the genus Brucella, the number of procedures available for providing this information is quite limited. However, the following may be considered the most definitive.

(i) Measurement of the DNA purinepyrimidine base ratios. The molar proportions of guanine and cytosine in the bacterial DNA should be determined by the buoyant density method, using ultracentrifugation in $\mathrm{CsCl}$ gradients according to Schildkraut et al. (33). Measurements should be made on DNA extracted from agar-grown organisms by the lysozyme-Pronase-sodium dodecyl sulfate method according to Hoyer and McCullough (18).

Alternatively, the guanine plus cytosine base ratios may be calculated from the DNA melting point determined by the method of Marmur and Doty (21). Parallel tests should be conducted with DNA from at least one Brucella reference strain.

(ii) Comparison of DNA base sequences by hybridization studies. The base sequences of the DNA molecules isolated from organisms of a proposed new species may be directly compared with those of a Brucella reference strain by measurement of the efficiency with which their separated strands inhibit the recombination of isotopically labelled, separated + and strands from the reference strain DNA. Using the procedure of Hoyer and McCullough (18), the DNAs from all known Brucella species show $>90 \%$ similarity in base sequence.

(iii) Comparison of the electrophoretic patterns of acid-phenol-soluble proteins. This method compares the electrophoretic properties of structural proteins which are themselves genetically determined. Thus, it permits indirect comparison of the base sequences in those regions of the bacterial DNA coding for these proteins. The technique has been developed for use with Brucella strains by Morris (29).

It is essential that similar concentrations of protein should be applied to each gel. The protein migration patterns produced by extracts of the strains under examination must only be compared with patterns produced by extracts of reference strains run simultaneously. All known authentic Brucella species produce virtually identical patterns. In assessing a new isolate, the positions of all of the major protein bands and the majority of the minor bands should coincide with those of the reference strain if the organism is to be considered representative of the genus.

(iv) Measurement of the absorption spectra of the major cytochrome bands. This method has been proposed by Vershilova et al. (35) as an aid in classifying possible Brucella strains. The procedure recommended is that described by Dranovskaya and Kushnarev (12).

The "classical" Brucella species, B. abortus, $B$. melitensis, and $B$. suis, give two extinction maxima attributable to cytochrome $c$, at 522 to 524 and 552 to $554 \mathrm{~nm}$. Absorption due to cytochrome $a$, with an extinction maximum between 620 and $630 \mathrm{~nm}$, is weak with these strains. Strains of $B$. canis, B. ovis, B. neotomae, and the proposed species $B$. murium, in addition to some $B$. suis strains, give cytochrome $c$ extinction maxima between 524 and 530 and 554 and $560 \mathrm{~nm}$. In addition, these 
strains show pronounced absorption by cytochrome $a$, with extinction maxima between 620 and $630 \mathrm{~nm}$.

Thus, to be considered as a possible member of the Brucella genus, an organism must contain cytochrome $c$ and give light absorption maxima between 522 and 530 and 552 and $560 \mathrm{~nm}$ under the conditions described.

(v) Demonstration of serological crossreactions with the soluble antigens of Brucella reference strains. It is well established that the intracellular antigens of all known members of the Brucella genus show extensive cross-reactions in serological tests (8-10). Furthermore, the intracellular antigens of Brucella spp. show little or no cross-reaction with the antigens of genetically unrelated organisms.

Serological cross-reactions involving antibodies reacting with the lipopolysaccharideprotein agglutinogen complexes of smooth Brucella species cannot be accepted as unequivocal evidence of membership of the genus. Antibodies directed against these agglutinogens cross-react extensively with Yersinia enterocolitica 0:9 $(1,6,11,19)$ and, to a lesser extent, with Salmonella serotypes of Kauffmann-White group N $(5,38)$, Vibrio cholerae (13), and Francisella tularensis $(14,15)$.

Similarly, agglutination reactions with monospecific antisera to the $\mathrm{A}$ and $\mathrm{M}$ determinants of $B$. abortus and B. melitensis, prepared according to Wilson and Miles (37), are unreliable for identification at the genus level, as $Y$. enterocolitica $0: 9$ also cross-reacts with the $\mathrm{A}$ determinant (6; B. Huvell, Ph.D. thesis, University of Stockholm, Stockholm, Sweden, 1973).

It is recommended that the antigenic relationship of a proposed Brucella isolate to Brucella reference strains should be determined by immunodiffusion and preferably also by immunoelectrophoresis of soluble antigens released by disruption of the organisms and freed of lipopolysaccharide-protein agglutinogen by high-speed centrifugation.

The extracts are standardized in terms of protein concentration, and this should be stipulated in all cases.

Immiunodiffusion and immunoelectrophoresis of the extracts against hyperimmune antisera to smooth and rough Brucella reference strains are performed under conditions similar to those described by Baughn and Freeman (3). The antisera used may be prepared by repeated intramuscular and subcutaneous injection of rabbits with disrupted Brucella organisms in Freund incomplete adjuvant, followed by increasing doses of live organisms. These sera should give at least six precipitation lines common to all Brucella reference strains on diffusion through agar gels against extracts of the organisms prepared by the method described.

The intracellular antigens of the organism under examination should give reactions of identity with the majority of precipitating components of Brucella reference strains before acceptance as a member of the genus. Cross-reaction with one or two intracellular Brucella antigens would not be sufficient to warrant acceptance.

The patterns produced on immunoelectrophoresis of cell-free extracts should also show coincidence in the positions of the majority of the precipitating components of the strain under examination and of Brucella reference strains.

It is recommended that all of these criteria should be fulfilled before an organism is finally accepted as a new member of the genus Brucella. However, it is realized that most of the procedures described are beyond the scope of the routine laboratory. Thus, it is recommended that new isolates should be submitted to a reference laboratory before proposal as a new species or biotype of Brucella.

Classification of the genus into species and biotypes. It is recognized that organisms identified as members of the genus Brucella possess a range of properties which can be clustered into species or biotypes, but clearly defined boundaries between species do not exist in all cases. For convenience of identification, it is recommended that strains should be classified into species on the basis of (i) preferred natural host, (ii) sensitivity to Brucella phages, and (iii) oxidative metabolic profiles.

Phage sensitivity tests are done using the Tbilisi ( $\mathrm{Tb}$ ) phage (also known as B. abortus phage, strain 3) and one of the wider host range phages, either M51 or S708 of Moreira-Jacob (27) or Weybridge phage (30). As M51, S708, and Weybridge phage all have identical host ranges $(30,31)$, it is necessary to use only one for typing purposes. As it is readily available, the Weybridge phage is recommended.

The phages are used at two concentrations, routine test dilution (RTD) and 10,000 times the RTD $\left(10^{4}\right.$ RTD), as recommended by the Subcommittee on Taxonomy of the Genus Brucella (34) using the method described elsewhere $(2,28)$. Strains for examination must be in the smooth phase as nonsmooth variants, even of susceptible species, are resistant to phage.

All smooth $B$. abortus strains are lysed by $\mathrm{Tb}, \mathrm{M} 51, \mathrm{~S} 708$, and Weybridge at RTD and $10^{4}$ RTD. All B. melitensis strains are resist- 


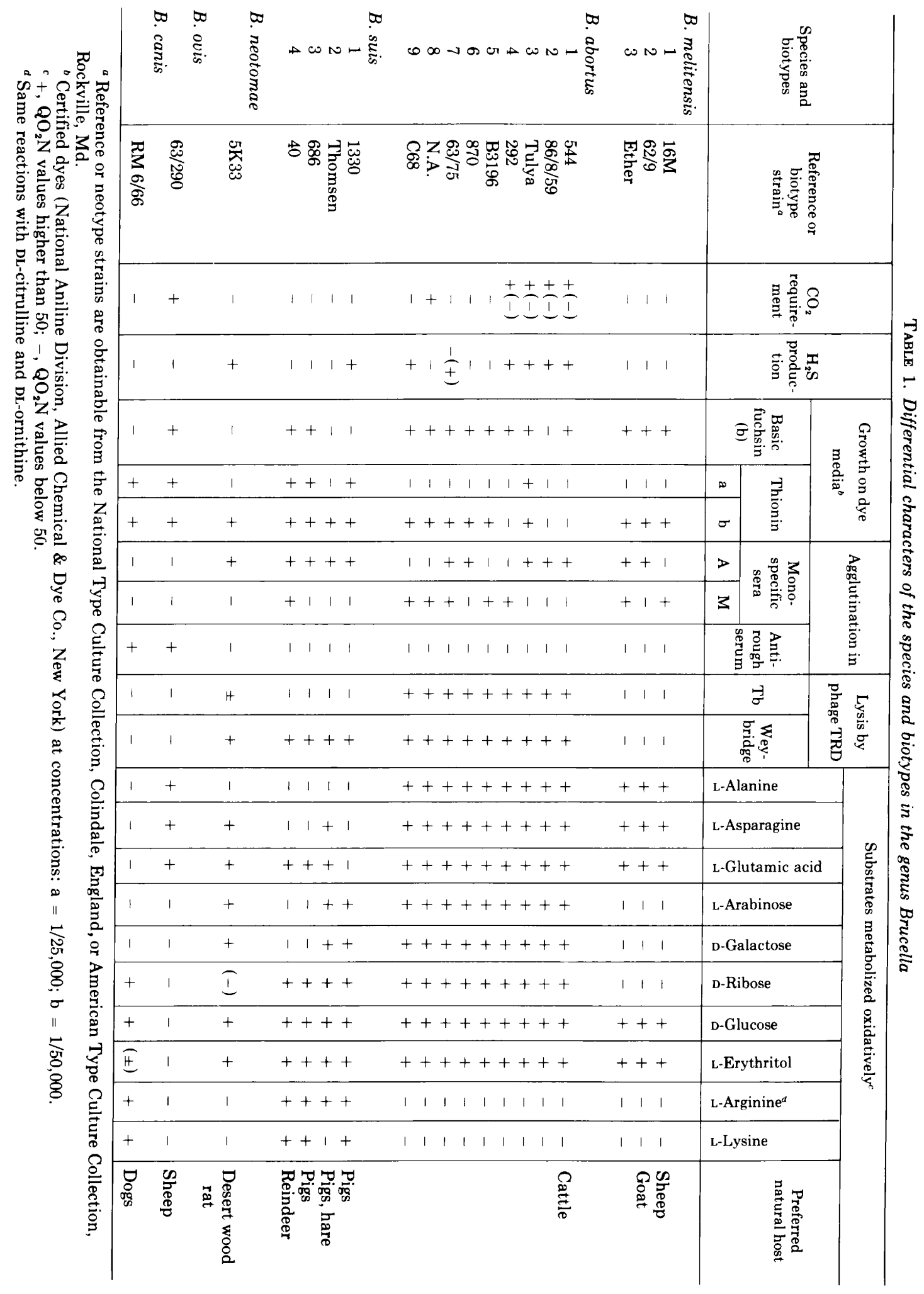


ant to all of these phages at both RTD and $10^{4}$ RTD. All smooth $B$. suis strains are resistant to Tb phage at RTD but are lysed at $10^{4}$ RTD. They are all lysed by M51, S708, or Weybridge at RTD and $10^{4}$ RTD.

$B$. neotomae strains are only partially susceptible to $\mathrm{Tb}$ phage, producing a few isolated plaques at RTD. They are completely lysed by Tb phage at $10^{4}$ RTD. They are also lysed at RTD and $10^{4}$ TRD by M51, S708, and Weybridge phages. $B$. ovis and $B$. canis strains are invariably resistant to all of these phages at RTD and $10^{4}$ RTD.

Oxidative metabolic profiles are compared by manometric measurement of oxidation rates for various carbohydrate and amino acid substrates (23-26). The methods recommended are described by Morgan and Gower (28) and Alton and Jones (2). The oxidative metabolic profiles of the recognized Brucella species and biotypes are summarized in Table 1.

Subdivision of the species into biotypes is made on the basis of $\mathrm{CO}_{2}$ requirement on primary isolation, $\mathrm{H}_{2} \mathrm{~S}$ production, sensitivity to inhibition by basic fuchsin and thionin dyes, and reaction with monospecific antisera to $\mathrm{A}$, $\mathrm{M}$, and $\mathrm{R}$ antigens. Oxidative metabolic profiles also aid in differentiating the $B$. suis biotypes. The techniques recommended for these tests are those described by Morgan and Gower (28) and Alton and Jones (2). The characteristics of the recognized species and biotypes are summarized in Table 1.

Because the differences between species and biotypes are often quantitative and not qualitative, it is stressed that reference or neotype strains should always be included.

\section{SUMMARY}

A proposal for minimal standards for description of new species and biotypes of the genus Brucella is being prepared for submission for consideration by the International Committee on Systematic Bacteriology through its Judicial Commission. The present document outlines the characters which the Subcommittee on Brucella considers should be incorporated in the final document. It invites comments from readers at this stage.

In the first instance, the classification of an organism as a member of the genus should be based on the following criteria: gram-negative, coccobacillary morphology; a guanine plus cytosine content of the DNA of 56 to $58 \mathrm{~mol} \%$; a minimum of $90 \%$ homology with the DNA of reference strains in hybridization tests; disk electrophoretograms of acid-phenol-soluble proteins of identical pattern to reference strains; a cytochrome $c$ absorption spectrum with absorption maxima between 522 to 530 and 552 to 560 $\mathrm{nm}$; extensive serological cross-reactions of intracellular antigens with those of reference strains. Supporting evidence is obtained from cultural, biochemical, and pathogenic properties, although variations in these occur within the genus. Subdivision into species is dependent upon principal natural host, oxidative metabolic pattern, and phage sensitivity. Classification into biotypes is dependent upon $\mathrm{CO}_{2}$ requirement, $\mathrm{H}_{2} \mathrm{~S}$ production, dye sensitivity, and reaction with monospecific antisera to $A$ and $M$ antigens.

Any organism proposed as a new member of the genus or species should have characters which approximate the ranges quoted. In all cases, comparisons should be made with the reference or neotype strains described in $\mathrm{Ta}$ ble 1 .

\section{LITERATURE CITED}

1. Ahvonen, P., E. Jansson, and K. Aho. 1969. Marked cross-agglutination between Brucellae and a sub-type of Yersinia enterocolitica. Acta Pathol. Microbiol. Scand. 75:291-295.

2. Alton, G. G., and L. M. Jones. 1967. Laboratory techniques in brucellosis. W. H. O. Monogr. Ser. 55. World Health Organization, Geneva.

3. Baughn, R. E., and B. A. Freeman. 1966. Antigenic structure of Brucella suis spheroplasts. J. Bacteriol. 92:1298-1303.

4. Braun, W., and A. Bonestell. 1947. Independent variation of characteristics in $\mathrm{Br}$. abortus variants and their detection. Am. J. Vet. Res. 8:386-390.

5. Cioglia, L. 1950. Antigeni communi a brucelle e sal. monelle. G. Batteriol. Immunol. 42:81-90.

6. Corbel, M. J., and G. A. Cullen. 1970. Differentiation of the serological response to Yersinia enterocolitica and Brucella abortus in cattle. J. Hyg. 68:519-530.

7. Diaz, R., and N. Bosseray. 1973. Identification d'un composé antigénique specifique de la phase rugueuse (R) des Brucella. Ann. Rech. Vet. 4:283.

8. Diaz, R., L. M. Jones, D. Leong, and J. B. Wilson. 1968. Surface antigens of smooth brucellae. J. Bacteriol. 96:893-901.

9. Diaz, R., L. M. Jones, and J. B. Wilson. 1967. Antigenic relationship of Brucella ovis and Brucella melitensis. J. Bacteriol. 93:1262-1268.

10. Diaz, R., L. M. Jones, and J. B. Wilson. 1968. Antigenic relationship of the gram-negative organism causing canine abortion to smooth and rough brucellae. $J$. Bacteriol. 95:618-624.

11. Diaz, R., R. Lacalle, M. P. Medrano, and D. Leong. 1970. Immunobiological activities of the endotoxin from Yersinia enterocolitica strain M.Y.79. Proceedings of the Vth International Congress on Infectious Diseases, Vienna. Bacteria 2:11-17.

12. Dranovskaya, E. A., and V. M. Kushnarev. 1968. Tsitokhromy brutsell (Cytochromes of Brucella). $\mathrm{Zh}$. Mikrobiol. Epidemiol. Immunobiol. 12:3-5.

13. Feeley, J. C. 1969. Somatic O antigen relationship of Brucella and Vibrio cholerae. J. Bacteriol. 99:645-649.

14. Feinberg, R. J., and G. G. Wright. 1951. Factors influenc- 
ing the agglutination titration in human brucellosis. J. Immunol. 67:115-122.

15. Francis, E., and A. C. Evans. 1926. Agglutination, cross-agglutination and agglutinin absorption in tularaemia. Public Health Rep. 41:1273-1295.

16. Gerhardt, P. 1958. The nutrition of brucellae. Bacteriol. Rev. 22:81-98.

17. Henry, B. S. 1933. Dissociation in the genus Brucella. J. Infect. Dis. 52:374-402.

18. Hoyer, B. H., and N. B. McCullough. 1968. Polynucleotide homologies of Brucella deoxyribonucleic acids. J. Bacteriol. 95:444-448.

19. Hurvell, B., P. Ahvonen, and E. Thal. 1971. Serological cross-reactions between different Brucella species and Yersinia enterocolitica. Agglutination and complement fixation. Acta Vet. Scand. 12:86-94.

20. McCullough, N. B., and L. A. Dick. 1943. Growth of Brucella in a simple chemically defined medium. Proc. Soc. Exp. Biol. Med. 52:310-311.

21. Marmur, J., and P. Doty. 1962. Determination of the base composition of deoxyribonucleic acid from its thermal denaturation temperature. J. Mol. Biol. 5:109-118.

22. Meyer, K. F., and E. B. Shaw. 1920. A comparison of the morphologic, cultural and biochemical characteristics of $\mathrm{Br}$. abortus and $\mathrm{Br}$. melitensis. J. Infect. Dis. 27:173-184.

23. Meyer, M. E. 1964. The epizootology of brucellosis and its relationship to the identification of Brucella organisms. Am. J. Vet. Res. 25:553-557.

24. Meyer, M. E. 1966. Identification and virulence studies of Brucella strains isolated from eskimos and reindeer in Alaska, Canada and Russia. Am. J. Vet. Res. 27:353-358.

25. Meyer, M. E., and H. S. Cameron. 1961. Metabolic char acterization of the genus Brucella. I. Statistical evaluation of the oxidative rates by which type 1 of each species can be identified. J. Bacteriol. 82:387-395.

26. Meyer, M. E., and H. S. Cameron. 1961. Metabolic characterization of the genus Brucella. II. Oxidative metabolic patterns of the described biotypes. J. Bacteriol. 82:396-400.
27. Moreira-Jacob, M. 1968. New group of virulent bacteriophages showing differential affinity for Brucella species. Nature (London) 219:752-753.

28. Morgan, W. J. B., and S. G. M. Gower. 1966. Techniques in the identification and classification of Brucella, $p$. 35-40. In B. M. Gibbs and F. A. Skinner (ed.), Identification methods for microbiologists. Academic Press Inc., London.

29. Morris, J. A. 1973. The use of polyacrylamide gel electrophoresis in taxonomy of Brucella. J. Gen. Microbiol. 76:231-237.

30. Morris, J. A., and M. J. Corbel, 1973. Properties of a new phage lytic for Brucella suis. J. Gen. Virol. 21:539-544.

31. Morris, J. A., M. J. Corbel, and J. I. H. Phillip. 1973. Characterisation of three phages lytic for Brucello species. J. Gen. Virol. 20:63-73.

32. Rode, L. J., G. Oglesby, and V. T. Schuhardt. 1950. The cultivation of brucellae on chemically defined media. J. Bacteriol. 60:661-668.

33. Schildkraut, C. L., J. Marmur, and P. Doty. 1962 Determination of the base composition of deoxyribonucleic acid from its buoyant density in $\mathrm{CsCl}$. J. Mol. Biol. 4:430-443.

34. Stabelforth, A. W., and L. M. Jones. 1963. Report of the subcommittee on taxonomy of the genus Brucella. Int. Bull. Bacteriol. Nomencl. Taxon. 13:145-148.

35. Vershilova, P. A., E. A. Dranovskaya, and V. M. Kushnarev. 1972. Dopolnityel'nȳy sposob opryedyclyeniya prinadlyezhnosti backteriy k rodu Brucella (An additional method of determining the relationship of bacteria to the genus Brucella). Zh. Mikrobiol. Epidemiol. Immunobiol. 12:98-101.

36. White, P. G., and J. B. Wilson. 1951. Differentiation of smooth and nonsmooth colonies of brucellae. J. Bacteriol. 61:239-240.

37. Wilson, G. S., and A. A. Miles. 1932. The serological differentiation of smooth strains of the Brucella group. Br. J. Exp. Pathol. 13:1-13.

38. Wundt, W. 1959. Zur Frage der Antigengemeinschaften zwischen Brucellen und Bakterien anderer Gattungen. Z. Hyg. 145:556-563 